\title{
FACTORS ASSOCIATED WITH DURATION OF NAPS AMONG COMMUNITY-DWELLING ELDERLY: DATA FROM THE MULTICENTER STUDY FIBRA ${ }^{1}$
}

\author{
Ariene Angelini dos Santos-Orlandi², Maria Filomena Ceolim ${ }^{3}$, Sofia Cristina Iost Pavarini, Simone Camargo de \\ Oliveira-Rossignolo ${ }^{5}$, Aline Maino Pergola-Marconato ${ }^{6}$, Anita Liberalesso Neri ${ }^{7}$
}

${ }^{1}$ Taken from the dissertation - Napping and frailty: a study involving elderly from FIBRA Unicamp, presented to the Graduate
Nursing Program at Universidade Estadual de Campinas (UNICAMP) in 2013.
${ }^{2}$ Ph.D. in Health Sciences, School of Nursing, UNICAMP. Campinas, São Paulo, Brazil. E-mail: arieneangelini@yahoo.com.br
${ }^{3}$ Ph.D. in Nursing, Associate Professor, School of Nursing, UNICAMP. Campinas, São Paulo, Brazil. E-mail: fceolim@fcm.
unicamp.br
${ }^{4}$ Ph.D. in Education, Associate Professor, Gerontology Department, Universidade Federal de São Carlos. São Carlos, São Paulo, Brazil.
E-mail: sofiapavarini@gmail.com
${ }^{5}$ Doctoral Student in Health Sciences, School of Nursing, UNICAMP. Campinas, São Paulo, Brazil. E-mail: sicamargoo@yahoo.
com.br
${ }^{6}$ Ph.D. in Health Sciences, School of Nursing, UNICAMP. Campinas, São Paulo, Brazil. E-mail: aline_pergola@yahoo.com.br
${ }^{7}$ Ph.D. in Psychology, Full Professor, School of Education, UNICAMP. Campinas, São Paulo, Brazil. E-mail: anitalbn@uol.com.br

\begin{abstract}
This study aimed to analyze the association between the duration of the nap and the variables gender, age, education, family income, frailty levels and frailty criteria of community-dwelling elderly. This was a descriptive and cross-sectional study, an excerpt from the multicenter project Frailty in Elderly Brazilians. A total of 3,075 older adults were evaluated, aged 65 and over, using a sociodemographic questionnaire, question about nap (Minnesota Leisure Activity Questionnaire), phenotype of frailty proposed by Fried and screening test for cognitive impairment (Mini Mental State Examination). Descriptive analysis, Mann-Whitney and Kruskal-Wallis tests ( $\mathrm{p}<0.05)$ and multiple linear regression were applied. Ethical principles were respected. Most of the elderly participants napped (61.7\%), with an average of $53.4 \pm 42.7 \mathrm{~min} /$ day. There was an association between duration of naps and variables gender $(\mathrm{p}=0.002)$, frailty $(\mathrm{p}=0.022)$ and frailty criterion "hand grip strength" ( $\mathrm{p}=0.008)$. It was observed that the length of the naps is greater for male and frail elderly.
\end{abstract}

DESCRIPTORS: Aged. Nursing. Sleep.

\section{FATORES ASSOCIADOS À DURAÇÃO DOS COCHILOS ENTRE IDOSOS COMUNITÁRIOS: DADOS DO ESTUDO MULTICÊNTRICO FIBRA}

RESUMO: Objetivou-se analisar associação entre a duração do cochilo e as variáveis gênero, idade, escolaridade, renda familiar, níveis de fragilidade e os critérios de fragilidade de idosos comunitários. Estudo descritivo e transversal, recorte do projeto multicêntrico Fragilidade em Idosos Brasileiros. Foram avaliados 3.075 idosos, com idade de 65 anos ou mais, utilizando-se questionário sociodemográfico, questão sobre cochilo (Minnesota Leisure Activity Questionnaire), fenótipo de fragilidade proposto por Fried e o teste de rastreio de alterações cognitivas (Mini Exame do Estado Mental). Realizaram-se análise descritiva, testes Mann-Whitney e Kruskal-Wallis ( $p<0,05)$ e regressão linear múltipla. Os princípios éticos foram respeitados. A maioria dos idosos participantes cochilava ( $61,7 \%)$, com valores médios de 53,4 442,7 minutos/ dia. Houve associação entre a duração dos cochilos e as variáveis gênero $(p=0,002)$, fragilidade $(p=0,022)$ e o critério de fragilidade "força de preensão manual" ( $\mathrm{p}=0,008)$. Observou-se que a duração dos cochilos é maior entre idosos do gênero masculino e frágeis.

DESCRITORES: Idoso. Enfermagem. Sono. 


\title{
FACTORES ASOCIADOS A LA DURACIÓN DE LAS SIESTAS DE LOS ANCIANOS DE LA COMUNIDAD: DATOS DEL ESTUDIO MULTICÉNTRICO FIBRA
}

\begin{abstract}
RESUMEN: El objetivo fue analizar la asociación entre duración de la siesta y las variables género, edad, educación, ingreso familiar, niveles y criterios de fragilidad de los ancianos de la comunidad. El estudio fue descriptivo, transversal y parte del proyecto multicéntrico Fragilidad en ancianos brasileños. Se evaluaron 3075 personas, con 65 años y más, mediante cuestionario sociodemográfico, una pregunta sobre la siesta (Minnesota Leisure Activity Questionnaire), el fenotipo de fragilidad propuesto por Fried y el Mini Mental State Examination. Se realizó análisis descriptivo, las pruebas de Mann-Whitney y de Kruskal-Wallis $(\mathrm{p}<0,05)$ y una regresión lineal múltiple. Se respetaron los principios éticos. La mayoría hacía la siesta (61,7\%), con medias de 53,4 442,7 minutos/ día. Se observó una asociación entre duración de las siestas y el género $(p=0,002)$, la fragilidad $(p=0,022)$ y el criterio de fragilidad "fuerza de prensión manual" $(p=0,008)$. Se observó que la duración de las siestas es mayor entre los ancianos masculinos y frágiles.
\end{abstract}

DESCRIPTORES: Anciano. Enfermería. Sueño.

\section{INTRODUCTION}

Napping can be defined as a short rest period during which the activity decreases and the reactions to external stimuli are reduced. ${ }^{1}$ As age advances, napping during the day may increase. ${ }^{2}$ Authors affirm that it is common for the elderly to nap, mainly in cultures with a warmer climate, as napping is part of the normal daily routine and is considered a healthy lifestyle. ${ }^{3}$

Researchers affirm that frequent, unplanned and lengthy (90 minutes or more) daily napping can negatively affect the quality of nighttime sleep and may be associated with negative consequences for health, such as increased risk of morbidity, cardiovascular disease, falls and cognitive problems. ${ }^{4-5}$

In contrast with these negative effects, short daily naps can demonstrate positive effects. Although this issue has received relatively little attention in the research literature, evidence exists that naps can be beneficial provided that they occur at the right time of day and with the appropriate length. Short naps (less than 30 minutes) can be more beneficial than no naps, for example, due to the enhanced vigilance and improved performance of daily tasks. In addition, it can be considered an important stress coping mechanism and therefore have a beneficial effect. ${ }^{6}$

The literature signals that the naps increase as age advances. ${ }^{4}$ Nevertheless, the results have been inconsistent in terms of the variables gender, education and family income.

Studies appoint that napping is more prevalent among men.-8 On the other hand, some experts have found no significant results regarding sex. ${ }^{9}$
The influence of education and family income on elderly napping seems to be unclear. Some researchers found that high levels of education may be associated with naps among community elderly ${ }^{10}$ and others have affirmed that naps are associated with low education and low income. ${ }^{11}$

As regards the association between naps and frailty, the literature is very scarce. No study has verified such an association thus far. Rare studies on sleep in general have been found, with apparently inconsistent results. ${ }^{12-15}$

Sleep problems can aggravate the course of a mental comorbidity or illness, thus increasing the vulnerability to the development of frailty. Sleep disorders are characterized by biological processes similar to those observed in frailty. ${ }^{16}$ Authors affirm that sleep disorders and the frailty syndrome are increasingly common as age advances. ${ }^{17-18}$

In view of the inconsistent results on the association between the variables of interest and napping and the lack of studies on the association between frailty and napping, the objective in this study was to analyze the association between the length of napping and the variables gender, age, education, family income, levels of frailty and the frailty criteria for community-dwelling elderly.

As napping might signal comorbidities, ${ }^{3}$ studies of this type are suggested to avoid late interventions.

\section{METHOD}

A descriptive and cross-sectional study with a quantitative approach was undertaken. This research is an excerpt from the project Frailty in Brazilian Elderly (Fibra), developed in 17 Brazil- 
ian cities and conducted by researchers from four hubs (University of São Paulo at Ribeirão Preto, Campinas State University, Federal University of Minas Gerais and Rio de Janeiro State University). A multicenter and multidisciplinary project was undertaken that investigates the characteristics and prevalence of the biological frailty syndrome and associated variables, in probabilistic samples of elderly aged 65 and over.

This study sample comprised the elderly from the database of six out of seven cities in the Fibra Project - Unicamp hub, excluding the elderly from Campina Grande-PB $(n=389)$, for whom, due to operational difficulties, the nap data could not be collected. Thus, the final sample included 3,075 elderly community-dwellers from the following cities: Belém-PA $(n=721)$, Poços de Caldas-MG (n=389), Parnaíba-PI (n=484), Campinas -SP $(n=900)$, Ivoti-RS $(n=197)$ and Ermelino Matarazzo-SP $(\mathrm{n}=384)$.

These elderly were invited to participate in the research through home visits. The interviewers were previously trained in accordance with the rules established in a research manual. The interviewer presented him/herself and the research and, next, invited the elderly to participate. When (s)he) accepted to participate in the research, the interviewer agreed upon where to collected the data. The elderly received a card with the date, time and place where the data collection would take place.

For each city, simple random sampling was applied to the urban census sectors. The number of census sectors drafted corresponded to the ratio between the intended number of elderly in each location and the number of urban census sectors in each location. The sampling plan established that the minimum sample size estimated for a city with more than one million inhabitants was 601 elderly, for a $4 \%$ sampling error. For cities with less than one million inhabitants, the estimate was 385 elderly for a 5\% sampling error. In each city, quote of census sectors were preset for the interviewers to visit. In each census sector, a sample was recruited whose size corresponded to its presence in the actual distribution of the elderly population across the sectors drafted, according to data by the Brazilian Institute for Geography and Statistics (IBGE). All samples should contain quota of men and women belonging to the age groups from 65 till 69, 70 till 74, 75 till 79 and 80 years and over, respecting the proportionality of these segments' distribution in the elderly population living in the urban region. For each census sector, an oversample $25 \%$ larger than the intended number of elderly was planned, respecting the sex and age criteria to compensate for possible losses during the data collection.

The participants complied with the following inclusion criteria: age 65 years or over, understanding the instructions and being a permanent resident at the home and in the census sector. The exclusion criteria used, through observation, were the following: a) elderly with a severe cognitive deficit suggesting dementia, evidenced by problems related to memory, attention, orientation in time and space and communication or problems the interviewers observed; b) elderly using a wheelchair or temporary or permanently bedridden; c) patients with severe sequelae due to Cerebrovascular Accidents, with localized loss of strength and/or aphasia; d) patients with severe or unstable Parkinson's Disease with severe motility, speech or affection problems; e) patients with severe hearing or sight impairments that strongly hampered the communication; and f) end-of-life elderly.

The data collection started after the reading and signing of the Informed Consent Form, between September 2008 and June 2009. The interviewers were undergraduate and graduate students and health professionals who had received ten months of training. The data were collected during a single session, in schools, churches, primary health care services, community centers and clubs. The elderly's sociodemographic characteristics were collected, as well as measures of cognitive status, frailty and napping.

The elderly's cognition was assessed using the Mini Mental State Examination (MMSE), a test to screen for cognitive changes. ${ }^{19}$ Any elderly scoring above the cut-off point, according to the level of education, participated in this study. The cut-off points used were: 17 for illiterate people; 22 for elderly with 1 to 4 years of education; 24 for those with 5 to 8 years of education, and 26 for elderly with 9 or more years of education. ${ }^{20}$

The following variables were used to collect 
the elderly's sociodemographic characteristics: gender, age, marital status, color/race, education, family income in minimum wages, family arrangement, current work and retirement. These data were collected using a tool developed by the researchers of the Fibra Study.

To assess the frailty, the definition proposed by Linda Fried was used. ${ }^{17}$ The working definition of the frailty syndrome or phenotype contains five elements: 1) unintentional weight loss equal to or higher than $4.5 \mathrm{~kg}$ or $5 \%$ of the body weight in the previous year; 2 ) self-reported fatigue. The assertion that the elderly felt that he had to make a lot of effort to cope with tasks or was unable to cope with him common tasks on three or more weekdays was considered a sign of fatigue; 3 ) low gripping strength measured using portable hydraulic dynamometer in dominant hand, adjusted for sex and body mass index (BMI). Three manual gripping strength measures were taken, using the arithmetic average; 4) low level of energy consumption measured in kilocalories and adjusted for sex, assessed based on self-reported exercising and housework in the previous seven days; 5) low walking speed indicated by mean time spent to move $4.6 \mathrm{~m}$, with adjustments for sex and height. Three walking speed measures were taken, using the arithmetic average. According to the results obtained in the assessment of each of these five elements, the elderly is considered "frail" or "non frail" on that specific characteristic. The presence of three or more of the five phenotype characteristics mean frailty, one or two mean pre-frailty and no characteristic indicates a non frail elderly.

Concerning the naps, one question from the Minnesota Leisure Time Activities Questionnaire ${ }^{21}$ was part of the Fibra Study, with a view to the selfreported assessment of the naps. The elderly was asked whether he slept or napped during the day (yes or no). If yes, the elderly answered how much time per day he spent on the nap.

All ethical principles for research involving human beings were complied with, in accordance with National Health Council Resolution 196/96. The Fibra Study coordinator authorized the use of the data. This study received approval from the
UNICAMP Research Ethics Committee as an addendum to the Fibra Study (opinion 208/2007) on September $27^{\text {th }} 2011$.

For the data analysis, the statistical software Statistical Analysis System for Windows version 9.2 was used. Descriptive statistics were applied, as well as non-parametric tests for inferential statistics, due to the non-adherence to the normal distribution of the variables, verified by means of the Kolmogorov-Smirnov test. To compare the variables - levels of frailty, frailty criteria, gender, age range, education, income related to variable duration of naps - Mann-Whitney and KruskalWallis' non-parametric tests were applied. The Mann-Whitney test was used for comparison between two groups (categories), and the KruskalWallis test among three or more groups (categories). In the cases where the null hypothesis of the Kruskal-Wallis test was rejected, the post-test was applied.

Besides the comparisons involving the nonparametric tests, a multiple linear regression model was applied for the variable "duration of naps" with regard to the other co-variables, except for the frailty criteria. To use this model, the logarithmic transformation was applied in the response variables to achieve the premises of the model. The level of significance adopted for the statistical tests was $5 \%(p \leq 0.05)$.

\section{RESULTS}

The participants were female $(67.4 \%)$, between 65 and 69 years of age $(35.3 \%)$, married or who lived with a partner $(48.1 \%)$, followed by widowed $(36.1 \%)$; white $(53.7 \%)$, between one and four years of education $(50.1 \%)$, monthly family income between 1.1 and 3.0 minimum wages (48.8\%), living with their children only $(27.4 \%)$. The large majority of these elderly did not work at the time of the research $(85.0 \%)$, were retired $(76.2 \%)$ and revealed to be pre-frail (51.9\%). The majority napped during the day $(61.7 \%)$, with an average $53.4 \pm 42.7$ minutes/ day. The results of the comparison between the variables of interest and the duration of the naps and the Kruskal-Wallis post-test are displayed in Tables 1 and 2. 
Table 1 - Comparative analysis of the variables frailty, gender, age, education and income according to the duration of the naps. Brazil, 2008/2009

\begin{tabular}{|c|c|c|c|c|c|c|c|c|c|}
\hline \multirow[t]{2}{*}{ Variable $(n)^{*}$} & \multicolumn{9}{|c|}{ Duration of nap in minutes } \\
\hline & $\mathbf{N}$ & Mean & $\mathrm{SD}+$ & $\begin{array}{l}\text { Mini- } \\
\text { mum }\end{array}$ & Q1 & Median & Q3 & $\begin{array}{l}\text { Maxi- } \\
\text { mum }\end{array}$ & p-value \\
\hline Frailty $(1,771)$ & & & & & & & & & $0.022 \ddagger$ \\
\hline Non frail & 689 & 50.4 & 40.3 & 3.0 & 30.0 & 30.0 & 60.0 & 300.0 & \\
\hline Pre-frail & 913 & 54.2 & 44.1 & 1.0 & 30.0 & 40.0 & 60.0 & 360.0 & \\
\hline Frail & 169 & 61.8 & 44.6 & 2.0 & 30.0 & 60.0 & 60.0 & 240.0 & \\
\hline Gender $(1,799)$ & & & & & & & & & $0.002 \S$ \\
\hline Male & 650 & 57.0 & 42.8 & 1.0 & 30.0 & 60.0 & 60.0 & 360.0 & \\
\hline Female & 1,149 & 51.4 & 42.6 & 2.0 & 30.0 & 30.0 & 60.0 & 360.0 & \\
\hline Age range $(1,799)$ & & & & & & & & & $0.2311 \ddagger$ \\
\hline 65 to 69 years & 612 & 52.8 & 41.5 & 5.0 & 30.0 & 30.0 & 60.0 & 240.0 & \\
\hline 70 to 74 years & 538 & 53.6 & 46.0 & 2.0 & 20.0 & 30.0 & 60.0 & 360.0 & \\
\hline 75 to 79 years & 375 & 52.2 & 38.9 & 2.0 & 30.0 & 40.0 & 60.0 & 240.0 & \\
\hline 80 years and over & 274 & 56.3 & 43.7 & 1.0 & 30.0 & 60.0 & 60.0 & 360.0 & \\
\hline Education $(1,797)$ & & & & & & & & & $0.0714 \ddagger$ \\
\hline zero years & 341 & 53.8 & 46.7 & 1.0 & 30.0 & 30.0 & 60.0 & 360.0 & \\
\hline 1 to 4 years & 901 & 51.4 & 40.2 & 2.0 & 30.0 & 30.0 & 60.0 & 300.0 & \\
\hline 5 to 8 years & 327 & 56.9 & 43.9 & 5.0 & 30.0 & 40.0 & 60.0 & 240.0 & \\
\hline 9 years or more & 228 & 56.1 & 44.4 & 5.0 & 30.0 & 60.0 & 60.0 & 360.0 & \\
\hline Family income $(1,510)$ & & & & & & & & & $0.1187 \ddagger$ \\
\hline 0 to $1.0 \mathrm{MW} \mid$ & 168 & 51.2 & 39.5 & 5.0 & 30.0 & 30.0 & 60.0 & 240.0 & \\
\hline 1.1 to $3.0 \mathrm{MW}$ & 721 & 51.6 & 41.7 & 1.0 & 30.0 & 30.0 & 60.0 & 360.0 & \\
\hline 3.1 to $5.0 \mathrm{MW}$ & 343 & 54.9 & 43.8 & 3.0 & 30.0 & 40.0 & 60.0 & 360.0 & \\
\hline 5.1 to $10.0 \mathrm{MW}$ & 179 & 57.5 & 42.4 & 3.0 & 30.0 & 50.0 & 90.0 & 300.0 & \\
\hline$>10.0 \mathrm{MW}$ & 99 & 52.7 & 33.7 & 5.0 & 30.0 & 40.0 & 60.0 & 180.0 & \\
\hline
\end{tabular}

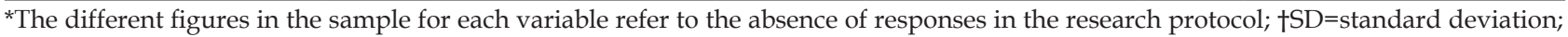
$\ddagger$-value obtained through the Kruskal-Wallis test; § p-value obtained through the Mann-Whitney test; ||MW=the Minimum Wage in Brazil corresponded to $R \$ 415,00$ in 2008 and $R \$ 465,00$ in 2009.

Table 2 - Kruskal-Wallis post-test related to the duration of the naps. Brazil, 2008/2009

\begin{tabular}{ccc}
\hline Variable & Comparison & Result \\
\hline \multirow{3}{*}{ Frailty } & Non frail - Pre-frail & $\mathrm{p}>0.05$ \\
& Non frail - Frail & $\mathbf{p}<0.05$ \\
& Pre-frail - Frail & $\mathrm{p}>0.05$ \\
\hline
\end{tabular}

A significant association was verified between the duration of the naps and the variables frailty and gender. For the frailty variable, the result of the Kruskal-Wallis post-test indicated a difference between non-frail and frail elderly. These differences can be observed through the mean scores and mainly the medians, in which the difference observed between the frail and non-frail elderly corresponded to 30 minutes. The frail elderly present a longer duration of the naps when compared to the non-frail elderly. For the gender variable, a significant difference was also observed between the groups, mainly when considering the medians. Men nap longer than women. For the other variables, no significant differences were observed.
Linear regression analysis was applied to assess how the variables selected in the study influence the duration of the elderly's naps. Table 3 displays these results.

\section{Table 3 - Results of linear regression analysis for duration of naps. Brazil, 2008/2009}

\begin{tabular}{lcc}
\hline Parameter & Coefficient & p-value* \\
\hline Intercept & 4,05 & $<0,001$ \\
Frailty & & \\
$\quad$ Non frail & $-0,31$ & $<0,001$ \\
$\quad$ Pre-frail & $-0,26$ & 0,005 \\
$\quad$ Frail (ref.) & - & - \\
Gender & & \\
$\quad$ Male & 0,12 & 0,045 \\
$\quad$ Female (ref.) & - & - \\
Age range & & \\
$\quad$ 65-69 years & $-0,05$ & 0,4605 \\
$\quad 70-74$ years & $-0,09$ & 0,1556 \\
$\quad$ 75-79 years & $-0,02$ & 0,7358 \\
$\quad$ 80 years and older (ref.) & - & - \\
Education & &
\end{tabular}




$\begin{array}{lcc}\text { 0 years } & -0,14 & 0,0835 \\ \text { 1-4 years } & -0,13 & 0,0658 \\ \text { 5-8 years } & 0,01 & 0,9496 \\ \text { 9 years or older (ref.) } & - & - \\ \text { Income } & & \\ \text { 0.0-1.1 minimum wages } & -0,02 & 0,8248 \\ \text { 1.1-3.0 minimum wages } & -0,05 & 0,6280 \\ \text { 3.1-5.0 minimum wages } & 0,01 & 0,9613 \\ \text { 5.1-10.0 minimum wages } & 0,08 & 0,4347 \\ \text { > 10.0 minimum wages (ref.) } & - & - \\ \text { *The logarithmic transformation was applied; †ref.: reference cate- } \\ \text { gory for the analysis. }\end{array}$

The results appointed that the variables frailty and gender significantly affect the duration of the elderly community dweller. The estimated coefficients suggest a drop in the duration of the naps among the non frail and pre-frail elderly when compared to the frail participants, and an increase in that duration among male when compared to female individuals. The model obtained showed an explanation coefficient $\left(\mathrm{R}^{2}\right)$ of $2.76 \%$. Table 4 presents the results of the comparison among the five frailty criteria and the duration of the naps.

Table 4 - Comparative analysis of five frailty criteria according to duration of naps. Brazil, 2008/2009

\begin{tabular}{|c|c|c|c|c|c|c|c|c|c|}
\hline \multirow[b]{2}{*}{ Variable (n) } & \multicolumn{9}{|c|}{ Duration of nap in minutes } \\
\hline & $\mathbf{N}$ & Mean & $\mathrm{SD}^{*}$ & $\begin{array}{l}\text { Mini- } \\
\text { mum }\end{array}$ & Q1 & Median & Q3 & Maximum & p-value \\
\hline Weight loss ${ }^{\ddagger}(1,695)$ & & & & & & & & & 0.3416 \\
\hline Non frail & 1,382 & 52.5 & 41.6 & 1.0 & 30.0 & 30.0 & 60.0 & 360.0 & \\
\hline Frail & 313 & 56.7 & 47.5 & 2.0 & 30.0 & 40.0 & 60.0 & 360.0 & \\
\hline Fatigue ${ }^{\ddagger}(1,742)$ & & & & & & & & & 0.0744 \\
\hline Non frail & 1,336 & 52.2 & 40.4 & 1.0 & 30.0 & 30.0 & 60.0 & 300.0 & \\
\hline Frail & 406 & 57.8 & 48.0 & 2.0 & 30.0 & 52.5 & 60.0 & 360.0 & \\
\hline Gripping strength ${ }^{\ddagger}(1,755)$ & & & & & & & & & 0.0080 \\
\hline Non frail & 1,390 & 52.2 & 42.2 & 2.0 & 30.0 & 30.0 & 60.0 & 360.0 & \\
\hline Frail & 365 & 58.7 & 45.6 & 1.0 & 30.0 & 60.0 & 60.0 & 360.0 & \\
\hline Exercising ${ }^{\ddagger}(1,785)$ & & & & & & & & & 0.0937 \\
\hline Non frail & 1,443 & 52.7 & 42.7 & 2.0 & 30.0 & 30.0 & 60.0 & 360.0 & \\
\hline Frail & 342 & 55.7 & 42.7 & 1.0 & 30.0 & 60.0 & 60.0 & 300.0 & \\
\hline Walking speed $\ddagger(1,760)$ & & & & & & & & & 0.1770 \\
\hline Non frail & 1,389 & 53.0 & 43.0 & 1.0 & 30.0 & 30.0 & 60.0 & 360.0 & \\
\hline Frail & 371 & 55.4 & 42.7 & 2.0 & 30.0 & 60.0 & 60.0 & 360.0 & \\
\hline
\end{tabular}

A significant association was found between the criterion "Palmar gripping strength" and the duration of the elderly people's naps. The elderly who were considered frail on this criterion, that is, elderly with low palmar gripping strength, napped longer than the participants without frailty on that factor.

\section{DISCUSSION}

Insufficient nighttime sleep can increase daytime sleepiness and negatively affect the elderly regarding the ability to stay alert during the entire day. It is hard to determine the sense of the causal relationship between the nap and the nighttime sleep disorder, and the sense of the relation can vary from person to person. Some individuals can start sleeping more during the day to "compensate for" the sleep lost during the night. Others can nap during the day and, thus, develop nighttime sleep difficulties. Bad nighttime sleep can be the precursor of a nap the next day instead of a consequence. ${ }^{4}$

Studies suggest that the duration of the naps exerts more influence on the sleep aspects when compared to the frequency. The time spent on the daytime naps can be of influence, both positive and negatively. Authors advise that the elderly's naps should be short, not exceeding 90 minutes. ${ }^{22}$ Longer naps contribute to frequent awakening at night, produce sleep inertia and worse quality of nighttime sleep. ${ }^{4}$ The short naps result in better functioning during the day, better cognitive and psychomotor performance, ${ }^{23}$ reduced subjective sleepiness and 
better mood, besides being considered an important stress coping mechanism. ${ }^{6}$

Based on the linear regression, the results appointed a significant effect of the variables frailty and gender on the duration of the participants' naps. Elderly considered to be non-frail (correlation -0.31 and $p<0.001$ ) or pre-frail (correlation -0.26 and $\mathrm{p}=0.005$ ) spent less time napping when compared to frail elderly. Male elderly (correlation 0.12 and $\mathrm{p}=0.045$ ) presented longer naps when compared to the female elderly.

The model obtained showed an explanation coefficient $\left(\mathrm{R}^{2}\right)$ of $2.76 \%$. This coefficient demonstrates a model with limited explanatory power. The variables used were not that relevant to explain the results found regarding the duration of the naps. There may be other variables influencing the naps beyond the ones selected in this study. In that sense, other variables should be investigated in the future, such as depression, comorbidities, sleep disorders, neurological diseases and cognitive dysfunction.

Concerning the frailty, authors from a North American study verified that the prevalence of excessive daytime sleepiness was higher among frail men. ${ }^{15}$ Another study in the United States found an association between daytime sleepiness and frailty, which stood out in the participants who reported sleep problems. For those authors, sleep disorders and frailty are highly prevalent, probably because of the advanced age and presence of multiple comorbidities. ${ }^{14}$

Frail elderly generally present comorbidities and greater probability of developing sequelae and disabilities. To develop frailty, the presence of multiple chronic conditions can be considered a risk factor. ${ }^{24}$ It is also known that unintentional napping may be a marker of some illness, physical and mental decline, to the extent that the time spent on naps increases. ${ }^{3}$ The association between sleep problems and frailty can be considered two-way, in which the frailty can lead to ruptures in the activity/rest rhythm with irregular cycles, which are frequently observed in elderly with chronic conditions. ${ }^{25}$

In this study, the association between duration of naps and gender $(\mathrm{p}=0.002)$, frailty levels $(p=0.022)$ and the frailty criterion "manual gripping strength" ( $p=0.008)$ was clear. Being male, frail and with reduced gripping strength is associated with longer duration of naps and perhaps with possible problems in elderly health.

Some authors explain that the association between sleep problems and frailty can be mediated through different mechanisms. The sleep problems can be a marker of comorbidities, such as cardiovascular diseases, condition of pre-frailty, depressive symptoms, cognitive dysfunction and functional disability. These aspects by themselves impair the sleep and increase the probability of individuals getting frail. In addition, sleep disorders and frailty or its components were both linked to biochemical alterations, including low levels of endogenous testosterone, reduction of the renal function and rise in pro-inflammatory cytokines. Any combination, or one of these routes, can mediate the increased probability of frailty among elderly people with sleep disorders. Nevertheless, these aspects and other confounding factors do not fully explain the associations between sleep disorders and frailty. Sleep disorders can be a marker of unknown factors that increase the probability of greater frailty. ${ }^{15}$

The longer time spent napping can indicate cultural habits and gender roles, and also be related to illnesses, frailty, physical and mental decline. According to the author, the personal choices and motivations, gender roles and social resources, interacting with health and behavioral competency, are determinants of the elderly people's time use. ${ }^{26}$

In this study, a significant association was verified between the criterion "Palmar gripping strength" and the duration of the elderly's naps. North American researchers verified that their study participants who scored on one or more frailty aspects suffered from excessive daytime sleepiness. For the women, an association was found between respiratory problems during sleep and low manual gripping strength. This association between low manual gripping strength and respiratory problems during sleep can be explained. The post-menopause can be a factor predisposing to the drop in muscle strength, and this relation may be mediated by the increased incidence of respiratory problems during sleep among women. Physiopathological changes during respiratory sleep disorders include inflammatory and hormonal routes, which can accelerate the drop in muscle mass and strength. ${ }^{13}$

Weight loss can result in general flaccidity of the muscle tonus, which could increase the collapse 
of the airways, contributing to respiratory sleep disorders. ${ }^{15}$ In addition, the loss of muscle mass and strength is provoked by the weight loss, largely due to changes in the senses of smell and taste and to dental problems, which are common among the elderly. This loss of muscle mass and strength can be called sarcopenia and increases after the age of 65 years, implies a drop in hormone levels, increase in inflammatory mediators, changes in the proteincalorie intake during ageing and functional disability. ${ }^{27}$ Sarcopenia results in the decrease and atrophy of the fast-twitch muscle fibers, with a consequent predominance of the slow-twitch fibers ${ }^{28}$ and causes great impact on the functional ability. ${ }^{26}$

Sarcopenic elderly have reduced competence to accomplish activities of daily living, becoming inactive, less engaged in social, leisure and recreation activities and with less interpersonal contacts, which could cause changes in the circadian rhythms, leading to highly irregular sleep and alert hours. Under that circumstance, they could nap for a long time. ${ }^{14,26}$ In addition, the low palmar gripping strength is associated with the presence of chronic conditions, low nutritional status, inflammatory conditions and low level of exercising, being responsible for increased functional disability and dependence and reduced mobility. ${ }^{27}$

When considering the study findings, the relevance is perceived of including sleep among the elderly's health items to be assessed, especially the presence and duration of the naps, as they can directly influence this population's health and represent a predictor of problems. On the other hand, programmed naps can offer benefits for the elderly and, thus, represent a health promotion and disease prevention intervention.

This study presents a series of strengths, including the original character of the theme, the large sample size, the nationwide range, the fact that the elderly are community dwellers and were not selected based on sleep disorders or frailty conditions and the validated frailty measures, identical to those used in the definition proposed by Linda Fried. At the start of the study, elderly with cognitive deficits were excluded, which could influence or even alter the findings.

On the other hand, the study also comes with some limitations. The results may not apply to other elderly groups in different contexts. The analyses were adjusted to different factors, but the possibility of residual confusion cannot be eliminated. Only objective sleep measures were used, which would reduce their stability. The research design was crosssectional, and no causal relations can be established between the variables. In addition, excessive daytime sleepiness and the presence of comorbidities that can influence the nap and/or frailty were not assessed in this study.

When reflecting on the practical implications of these findings, the need is highlighted for an indepth assessment of the elderly visiting the health services, aiming to study sleep-related issues, with a view to the early detection of problems and the development of actions that minimize the complaints, thus avoiding late interventions.

Also, the temporal clues should be strengthened, involving activities that are meaningful to the elderly, in the attempt to minimize the changes related to the circadian rhythm resulting from ageing. In addition, the sleep variable should be included in the frailty phenotype, as the sleep disorders/ napping can be an early marker of this syndrome.

\section{CONCLUSION}

An association was found between the duration of the elderly's naps and the variables gender, frailty levels and the frailty criterion "palmar gripping strength". The duration of the naps was longer among male and frail elderly with low gripping strength.

The importance of the nurses should be highlighted in the development of an expanded view on the relevance of frailty in the duration of the elderly's naps, considering that napping can be a marker of an underlying pathology, physical and mental decline, to the extent that the time spent on naps increases.

In that sense, the several studies that found an association between frailty and the presence of comorbidities are also highlighted. The health team as a whole should be prepared to intervene competently, aiming to improve these elderly's quality of life. In that sense, the health professionals from the primary health care services should be prepared for the early detection of problems, through more elaborate assessments, which should include aspects of the elderly's sleep and frailty. 
Future studies on this theme should be developed, in view of the lack of studies in the literature. Comorbidities should be included in this analysis, in view of their close relationship with napping and frailty.

\section{ACKNOWLEDGEMENTS}

Acknowledgements for the funding of the Coordination for the Improvement of Higher Education Personnel (CAPES) and to the coordinator of the Fibra Study, Prof. Anita Liberalesso Neri, for her generosity in making available the database, contributing to the publication of this article.

\section{REFERENCES}

1. Yilmaz H. Comparison of motor activity and sleep in patients with complex partial seizures on levetiracetam treatment and a group of healthy subjects. Behav Neurol. 2007; 18(3):165-70.

2. Santos AA, Ceolim MF, Neri AL. Sleep complaints among Brazilian senior citizens from municipalities with different Human Development Indices. Rev Latino-Am Enfermagem. 2012 Set-Out; 20(5):917-26.

3. Fang $\mathrm{W}$, Li Z, Wu L, Cao Z, Liang Y, Yang H, et al. Longer habitual afternoon napping is associated with a higher risk for impaired fasting plasma glucose and diabetes mellitus in older adults: results from the Dongfeng-Tongji cohort of retired workers. Sleep Med. 2013; 14(10):950-4.

4. Ficca G, Axelsson J, Mollicone DJ, Muto V, Vitiello MV. Naps, cognition and performance. Sleep Med Rev. 2010 Aug; 14(4):249-58.

5. Theadom A, Cropley M, Kantermann T. Daytime napping associated with increased symptom severity in fibromyalgia syndrome. BMC Musculoskelet Disord. 2015; 16(1):13.

6. Liu X, Zhang Q, Shang X. Meta-analysis of selfreported daytime napping and risk of cardiovascular or all-cause mortality. Med Sci Monit. 2015; 21:1269-75.

7. Jung KI, Song CH, Ancoli-Israel S, Barrett-Connor E. Gender differences in nighttime sleep and daytime napping as predictors of mortality in older adults: the Rancho Bernardo Study. Sleep Med. 2013 Jan; 14(1):12-9.

8. Baoying $\mathrm{H}$, Hongjie $\mathrm{C}$, Changsheng $\mathrm{W}$, Peijian $\mathrm{W}$, Wingfei L, Yinghua L et al. Association of napping and night-time sleep with impaired glucose regulation, insulin resistance and glycated haemoglobin in Chinese middle-aged adults with no diabetes: a crosssectional study. BMJ Open. 2014; 4(7):e004419.

9. Owens JF, Buysee DJ, Hall M, Kamarck TW, Lee L, Strollo PJ et al. Napping, nighttime sleep, and cardiovascular risk factors in mid-life adults. J Clin
Sleep Med. 2010; 6(4):330-5.

10. Tanabe N, Iso H, Seki N, Suzuki H, Yatsuya H, Toyoshima $\mathrm{H}$ et al. Daytime napping and mortality, with a special reference to cardiovascular disease: the JACC study. Int J Epidemiol. 2010; 39(1):233-43.

11. Gu D, Sautter J, Pipkin R, Zeng Y. Sociodemographic and health correlates of sleep quality and duration among very old Chinese. Sleep. 2010; 33(5):601-10.

12. Dam TT, Ewing S, Ancoli-Israel S, Ensrud K, Redline S, Stone K. Association between sleep and physical function in older men: the osteoporotic fractures in men sleep study. J Am Geriatr Soc. 2008 Sep; 56(9):1665-73.

13. Endeshaw YW, Unruh ML, Kutner M, Newman AB, Bliwise DL. Sleep-disordered breathing and frailty in the Cardiovascular Health Study cohort. Am J Epidemiol. 2009 May; 170(2):193-202.

14. Fragoso CAV, Gahbauer EA, Ness PHV, Gill TM. Sleep-wake disturbances and frailty in communityliving older persons. J Am Geriatr Soc. 2009 Nov; 57(11):2094-100.

15. Ensrud KE, Blackwell TL, Redline S, Ancoli-Israel S, Paudel ML, Cawthon PM, et al. Sleep disturbances and frailty status in older community-dwelling men. J Am Geriatr Soc. 2009 Nov; 57(11):2085-93.

16. Fragoso CAV, Gill TM. Sleep complaints in community-living older persons: a multifactiorial geriatric syndrome. J Am Geriatr Soc. 2007 Nov; 55(11):1853-66.

17. Fried LP, Tangen CM, Walston J, Newman AB, Hirsch C, Gottdiener J, et al. Frailty in older adults: evidence for a phenotype. J Gerontol Biol Sci Med Sci. 2001 Mar; 56(3):M146-56.

18. Oliveira LPBA, Menezes RMP. Representations of frailty for elderly within the family health strategy context. Texto Contexto Enferm. 2011 Abr-Jun; 20(2):301-9.

19. Folstein MF, Folstein SE, McHugh PR. Mini-Mental State. A practical method for grading the cognitive status of patients for the clinician. J Psychiatr Res. 1975 Nov; 12(3):189-98.

20. Brucki SMD, Nitrini R, Caramelli P, Bertolucci PHF, Okamoto IH. Sugestões para o uso do Mini-Exame do Estado Mental no Brasil. Arq Neuropsiquiatr. 2003; 61(3-B):777-81.

21. Taylor HL, Jacobs DR, Schucker B, Knudsen J, Leon AS, Debacker G. A questionnaire for the assessment of leisure time physical activities. J Chronic Disease. 1978 Dec; 31(12):741-55.

22. Monk TH, Buysse DJ, Carrier J, Billy BD, Rose LR. Effects of afternoon siesta naps on sleep, alertness, performance, and circadian rhythms in the elderly. Sleep. 2001 May; 24(6):680-7.

23. Campbell SS, Stanchina MD, Schlang JR, Murphy PJ. Effects of a month-long napping regimen in older individuals. J Am Geriatr Soc. 2011 Feb; 59(2):224-32. 
24. Ávila-Funes JA, Helmer C, Amieva H, BarbergerGateau P, Goff ML, Ritchie K, et al. Frailty among community-dwelling elderly people in France: the three-city study. J Gerontol A Biol Sci Med Sci. 2008 Oct; 63A(10):1089-96.

25. Ensrud KE, Blackwell TL, Ancoli-Israel S, Redline S, Cawthon PM, Paudel ML, et al. Sleep disturbances and risk of frailty and mortality in older men. Sleep Med. 2012 Dec; 13(10):1217-25.

26. Marincolo JCS. Indicadores de fragilidade e tempo despendido em atividades em idosos: dados do FIBRA
Campinas [dissertação]. Campinas (SP): Universidade Estadual de Campinas. Programa de Pós-Graduação em Gerontologia; 2010.

27. Silva TAA, Junior AF, Pinheiro MM, Szejnfeld VL. Sarcopenia associada ao envelhecimento: aspectos etiológicos e opções terapêuticas. Rev Bras Reumatol. 2006 Nov-Dez; 46(6):391-7.

28. Miljkovic N, Lim JY, Miljkovic I, Frontera WR. Aging of skeletal muscle fibers. Ann Rehabil Med. 2015 Apr; 39(2):155-62. 